\title{
Accounting students' perceptions of online learning in the age of industry 4.0
}

\author{
Tran Van Tung ${ }^{\mathrm{a}^{*}}$, Ngo Ngọc Nguyen Thao ${ }^{\mathrm{a}}$ and Tran Phương Hai ${ }^{\mathrm{a}}$
}

${ }^{a}$ Ho Chi Minh City University of Technology (Hutech), Vietnam

\section{H R O N I C L E A B S T R A C T}

Article history:
Received: June 20, 2020
Received in revised format:
August 302020
Accepted: September 18,2020
Available online:
September 18,2020
Keywords:
Students' perspectives
Accounting
Online learning
Industry 4.0

\section{Introduction}

According to Kagermann (2014) and Bonekamp (2015), the rapid pace of technological developments related to Artificial Intelligence (A.I) has led to Industry 4.0, which enables mankind to access a huge amount of information using the Internet. Industry 4.0 provides an approach in which human, information and communication can develop together. Initially, the Fourth Industrial Revolution started in Germany and eventually spread to the US, Japan, and China. The core factors of Industry 4.0 are Artificial Intelligence (A.I), Internet of Things (IoT), and Big Data. This is, indeed, an industrial revolution that has never happened before, and it can create many opportunities as well as challenges for all aspects of life (Panigrahi et al., 2018). The essence of Industry 4.0 is the application of technology, data science and the use of artificial intelligence in production and social life. Industry 4.0 has brought many favorable conditions to help people discover new knowledge, increase the size and quality of the economy, especially in the field of production; however, it has also brought many challenges that force employees and strategic planners to change their plans accordingly. Among all things, modern education, especially higher education, has been affected strongly by the Industrial Revolution. In accordance with Vietnam's policies, recently, the country has been implementing the radical and comprehensive renovation of education, especially higher and post-graduate education. However, due to the strong impact of Industry 4.0 on education, universities have to change their objectives, curriculum, and teaching methods. Apparently, online teaching, along with the various teaching tools invented in the digital age, has been dramatically changing the process of teaching and learning at universities, in which it helps Vietnam education with modernization and global integration. On the other hand, it has also raised a lot of issues that teachers and administrators must consider when they adjust the teaching methods to deliver lessons more effectively and efficiently (Dung et al., 2018).

\footnotetext{
* Corresponding author.

E-mail address: tv.tung@hutech.edu.vn (T. V. Tung) 
Students' perceptions and their willingness to participate in online courses regularly play a crucial part in the success of the application of online learning.

This paper discusses the positive impacts of several factors on the quality of online learning methods when utilizing new inventions and tools from the era of Industry 4.0 to deliver lectures to accounting students at universities in Ho Chi Minh City; simultaneously, the study also identifies the relationship between accounting students' perceptions of online learning and the quality of such method, thereby proposing some implications to innovate current education system in order to keep up with the new educational trends in the Age of Industry 4.0.

\section{Literature review}

According to Alsabawy et al. (2016), educational institutions have invested in information systems to improve operational efficiency in order to increase the accessibility of education, improve self-efficacy, generate knowledge, enhance costeffectiveness, enable learner flexibility, and enhance the interactivity between campus, students, alumni, employers, and other relevant parties. Changes in technology and their impacts have severe influence on lesson delivery as well as the implementation of teaching methods. Industrial Revolution 4.0 brings opportunities and allow educational institutions in many countries, including developing ones such as Vietnam, to adjust their models of educational delivery. The use of technology to facilitate better learning and training conditions is gaining momentum worldwide, changing the awareness and reaction to the temporal and spatial problems associated with current learning and teaching methods (Panigrahi et al., 2018). Technology allows the implentation of online learning, which is an educational environment supported by the internet, so learners need to have some basic understanding of IT to get full benefits provided by the new educational system, such as receiving instructions, transferring documents, submitting assignments, taking online exams, reviewing lectures, etc. According to Kukulska-Hulme (2012), students can access online material and other resources utilizing IT to facilitate teaching and learning. Educational institutions have been trying to develop and apply technology to online teaching. In order to do this, lecturers and staffs need to have the basic understanding of Online learning to deliver lessons in the most efficient way possible; only by doing this can institutons convince and build trusts with students, the ones that will benefit directly from the online system. Educational institutions have been trying their best to implement this new online system, which can create a myriad of differences in the interaction between lecturers and learners in comparison with traditional learning. Students can engage in an environment that can provide various methods of participation (Dağhan \& Akkoyun-lu, 2016). According to Asiry (2017), lecturers' expertise in online teaching, students' readiness and willingness to switch to online learning, and the quality of the online programmes are those factors contributing to the success of online learning. The fact that students are accepting and trying to adapt to this new online system is really interesting and requires further investigation.

\section{Research methods and research hypotheses}

\subsection{Data and methodology}

Samples in the official research were chosen using convenience-sampling method, in which the questionnaire was sent directly to accounting students in universities in Ho Chi Minh City. The questionnaire also has a part to declare the authors' commitments to use the information for research purposes only, as well as to keep respondents' information confidential. EFA method requires large sample size. According to Bollen (1989), the minimum sample size for each question should be 5 observations. Therefore, with 36 questions, this research would require minimum sample size of $36 \times 5=180$ observations. In order to reach the minimum sample size, during the period from Jan 2020 to Apr 2020, the authors had sent a total of 1.200 questionnaires to accounting students in 20 universities in Ho Chi Minh City (60 students per university on average). Afterwards, 1.078 responses were collected; among them, 86 responses were invalid (mainly because they lack the required information). Therefore, the final sample size that was used in the observation was 992 . The research has 2 main phases: Preliminary and Official. In order to adjust and optimize the scales of measurement, preliminary research was conducted by directly interviewing accounting students in various universities in Ho Chi Minh City that are implementing online learning systems. Meanwhile, official research was conducted using quantitative method in which data was collected by direct interviews and questionnaire. Then, the information collected was processed and analyzed using SPSS and AMOS to arrive at the statistical result. The questionnaire consists of 36 questions in regard to 36 variables being used in the 8 scales of measurement in the research model. All variables showed good signs of reliability, and added value to the research. Specific sets of observations were measured using the 5 point Likert scale, from 1 - Completely disagree, to 5 - completely agree.

\subsection{Research models and hypotheses}

This study focuses on identifying the factors affecting students' perceptions of online learning system in universities in Ho Chi Minh City. In order to determine students' readiness, as well as increasing students' perceptions of online learning, the study was conducted after those universities had implemented the new system on some courses for accounting students. Some theoretical frameworks related to behaviours in information systems were applied to explain and predict users' behaviours in the implementation and continuous usage of the new online system, such as Diffusions of Innovation Theory (1962), Cognitive Model (Oliver, 1980), Social Cognitive Theory (Bandura, 1986), Technology Acceptance Model (Davis, 1989), Theory of Planned Behaviour (1991), Unified Theory of Acceptance and Use of Technology (Venkatesh et al., 2003), Information 
Systems Success Model (Delone \& McLean, 1992, 2003; Petter et al., 2013), Technology Continuance Theory (Liao et al., 2009) and Integrated Flow Framework (Dağhan \& Akkoyunlu, 2016). Information Systems Success Model have been expanded in several models that estimate the success of information systems in different conditions, and those relationships were examined. In the first model introduced by DeLone \& McLean in 1992, system quality and information quality were founded to affect the acceptance and satisfaction of users directly. In 2003, DeLone \& McLean revised this model and added 2 more variables, which were quality of service and usage intention. The model was then revised again in 2013 and several variables were added, including organizational goals, organizational characteristics, users' characteristics related to IT, social characteristics, and readiness to adapt to the new technological environment (Petter et al., 2013), all of which formed the independent variables of the model; meanwhile, other technological concepts (usage, user satisfaction, and net benefits) constituted the dependent variables. Although it has already been 22 years since the initial conception of the model, system quality, information quality, usage, and other satisfaction variables still maintain an appropriate level of explanation in many frameworks and models. Therefore, those variables are considered to be among the important core variables in the final form of the authors' model. Variables of system quality, information quality, and service quality, which are adapted from Information Systems Success Model, have positive impact on satisfaction (DeLone \& McLean, 2003). Satisfaction, confirmation, and continuance intention are adapted from Information Expectation Confirmation Model (Bhattacherjee, 2001), Cognitive Model (Oliver, 1980); Technology Continuance Model (Liao, Palvia \& Chen, 2009), and Integrated Flow Model (Dağhan \& Akkoyunlu, 2016). Aside from those, the variable of utilitarian value is also adapted from the research conducted by Chiu et al. (2007). Service quality refers to customers' perception of the overall quality of support provided by staffs. Satisfaction refers to perceptions regarding the satisfaction level of customers who interact with the systems directly. Confirmation refers to perceptions regarding the compability and harmony between users' expectations and actual performance of the system (Kim \& Oh, 2011). According to Parasuraman et al. (1994), quality of service is the difference between expectations and perceptions of outcome. In order to determine the level of satisfaction, users will compare the difference between their expectations before using the service with their actual experience after using it based on 5 factors: Trust, Empathy, Feedback, Tangibility, and Assurance. According to Liao et al. (2009), information quality, System quality, and Service quality have possible impact on users' satisfaction. Information quality and System quality have possible impact on perceived value, which can affect the perceptions and continuance intention of students. Information quality refers to perceptions regarding the format and design of the website, as well as its capacity to provide users with appropriate information. System quality refers to perceptions regarding qualities that are valued by users of the system in the online environment, such as steps to complete a task, accessibility, user-friendliness, and quick response. Outcome expectation refers to perceptions regarding the system's effectiveness and efficiency, users' ability to gather information completely and timely, sense of achievement, and whether or not the society is perceiving users as competitive human beings. Outcome expectation also refers to perceptions regarding keeping up to date, the ability to provide users with required knowledge and training while using the system. Aside from those, if the system is easy to operate, highly compatible, and can improve students' performance, users' perceptions and continuance intention will dramatically improve (Chiu et al., 2005). Based on the literature review and other existing frameworks, the authors constructed the following model and hypothesizes:

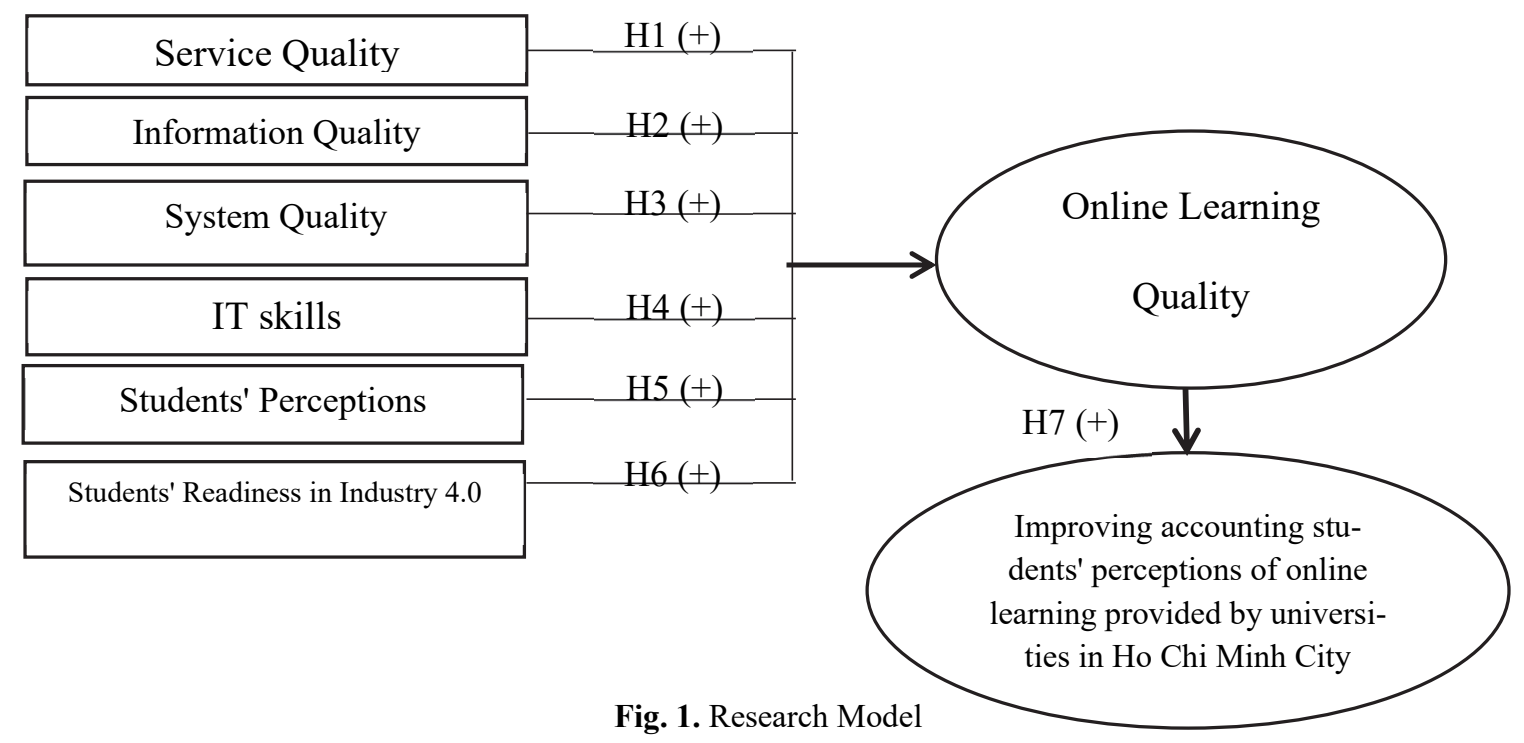

In order to determine the influence and importance of factors affecting the quality of online learning to improve accounting students' perceptions of this new learning method, several hypotheses were tested:

Hypothesis H1: The Service Quality has a positive (+) effect on the Online Learning Quality of the universities in Ho Chi Minh City. 
Hypothesis H2: The Information Quality has a positive (+) effect on the Online Learning Quality of the universities in Ho Chi Minh City.

Hypothesis H3: The System Quality has a positive (+) effect on the Online Learning Quality of the universities in Ho Chi Minh City.

Hypothesis H4: The IT skills has a positive (+) effect on the Online Learning Quality of the universities in Ho Chi Minh City.

Hypothesis H5: The Students' Perceptions has a positive (+) effect on the Online Learning Quality of the universities in Ho Chi Minh City.

Hypothesis H6: The Students' Readiness in Industry 4.0 has a positive (+) effect on the Online Learning Quality of the universities in Ho Chi Minh City.

Hypothesis H7: The Online Learning Quality has a positive $(+)$ effect on improving accounting students' perceptions of online learning provided by universities in Ho Chi Minh City.

\subsection{Model specification}

We develop a multivariate regression equation to test the research hypotheses as follows:

On a theoretical basis, the proposed regression equation reflects the correlation between factors affecting Online Learning Quality of the universities in Ho Chi Minh City. Follow the regression equation:

$$
C L H T T=\beta O+\beta_{1} C L D V+\beta_{2} C L T T+\beta_{3} C L H T+\beta_{4} K T S D+\beta_{5} C N S V+\beta_{6} S S S V+\varepsilon
$$

where $\beta_{0}, \beta_{1}, \beta_{2}, \beta_{3}, \beta_{4}, \beta_{5}$ and $\beta_{6}$ represent model regression coefficients and $\varepsilon$ stands the error term. Moreover, CLHTT represents The Online learning Quality as the Dependent variable.

Independent variables:

CLDV: Service Quality

CLTT: Information Quality

CLHT: System Quality
KTSD: IT skills

CNSV: Students' perceptions

SSSV: Students' Readiness

\section{Empirical results}

\subsection{Measurement scales}

By using Cronbach's Alpha to test reliability, it can be stated that all 36 of observable variables are qualified, and they all pass the test of reliability, since minimum item-total correlation of each factor is greater than 0.3 , and Cronbach's Alpha $>0.6$. If any of the observable variables is eliminated, Cronbach's Alpha value will decrease. Table 2 shows total results of the test of reliability.

Table 1

Summary of Cronbach's Alpha test results

\begin{tabular}{|c|c|c|c|c|c|}
\hline No. & Scale & $\begin{array}{c}\text { Number of } \\
\text { initial observed } \\
\text { variables }\end{array}$ & $\begin{array}{l}\text { Number of variables } \\
\text { observed after testing }\end{array}$ & $\begin{array}{c}\text { Cronbach's } \\
\text { Alpha }\end{array}$ & $\begin{array}{c}\text { Corrected Item- } \\
\text { Smallest Total } \\
\text { Correlation }\end{array}$ \\
\hline 1 & Service Quality (CLDV) & 5 & 5 & 0.908 & 0.677 \\
\hline 2 & Information Quality (CLTT) & 5 & 5 & 0.878 & 0.665 \\
\hline 3 & System Quality (CLHT) & 5 & 5 & 0.870 & 0.680 \\
\hline 4 & IT skills (KTSD) & 4 & 4 & 0.898 & 0.703 \\
\hline 5 & Students' perceptions (CNSV) & 5 & 5 & 0.865 & 0.612 \\
\hline 6 & Students' Readiness (SSSV) & 4 & 4 & 0.828 & 0.624 \\
\hline 7 & Online learning Quality (CLHTT) & 4 & 4 & 0.848 & 0.644 \\
\hline 8 & $\begin{array}{l}\text { Improving perceptions of accounting students in universities } \\
\text { in Ho Chi Minh City (SNT) }\end{array}$ & 4 & 4 & 0.942 & 0.846 \\
\hline
\end{tabular}

EFA discovery factor analysis

Exploratory Factor Analysis (EFA)

When analyzing EFA for scales in the research model, the author uses the Principal Component Analysis method with Varimax rotation and stops extracting elements with Eigenvalue $>1$. EFA results show KMO coefficient $=0.915$ and the Barlett test with Sig. $=.000(<.05)$ indicate that the EFA analysis is appropriate. 
Table 2

KMO Analysis and Bartlett's Test

\begin{tabular}{cll}
\hline Kaiser-Meyer-Olkin Measure of Sampling Adequacy. & & 0.915 \\
\hline Bartlett's Test of Sphericity & Approx. Chi-Square & 21893.376 \\
& Df & 630 \\
& Sig. & .000 \\
\hline
\end{tabular}

At Eigenvalue $=1.085>1$ extracted from 8 factors from 36 observed variables with a total variance extracted is $71.368 \%$ ( $>$ $50 \%$ ) and no new factors have been formed compared to the proposed research model. Thus, after EFA analysis, these 36 observed variables ensure the EFA analysis standard (satisfactory). No variables were excluded at this stage

Table 3

Total Variance Explained

\begin{tabular}{|c|c|c|c|c|c|c|c|}
\hline \multirow[t]{2}{*}{ Component } & \multicolumn{3}{|c|}{ Initial Eigenvalues } & \multicolumn{3}{|c|}{ Extraction Sums of Squared Loadings } & \multirow{2}{*}{$\begin{array}{c}\begin{array}{c}\text { Rotation Sums of } \\
\text { Squared Loadings }\end{array} \\
\text { Total }\end{array}$} \\
\hline & Total & $\%$ of Variance & Cumulative \% & Total & $\%$ of Variance & Cumulative \% & \\
\hline 1 & 10.084 & 28.011 & 28.011 & 10.084 & 28.011 & 28.011 & 6.345 \\
\hline 2 & 3.234 & 8.982 & 36.994 & 3.234 & 8.982 & 36.994 & 5.429 \\
\hline 3 & 2.459 & 6.831 & 43.824 & 2.459 & 6.831 & 43.824 & 6.151 \\
\hline 4 & 2.355 & 6.542 & 50.366 & 2.355 & 6.542 & 50.366 & 4.883 \\
\hline 5 & 2.308 & 6.410 & 56.776 & 2.308 & 6.410 & 56.776 & 4.564 \\
\hline 6 & 2.281 & 6.337 & 63.113 & 2.281 & 6.337 & 63.113 & 4.884 \\
\hline 7 & 1.894 & 5.260 & 68.373 & 1.894 & 5.260 & 68.373 & 3.615 \\
\hline 8 & 1.078 & 2.995 & 71.368 & 1.078 & 2.995 & 71.368 & 6.629 \\
\hline 9 & .671 & 1.863 & 73.231 & & & & \\
\hline
\end{tabular}

Using the EFA method, we analyze each variable separately to test the multidirectionality of the factors and evaluate the scale for the factors.

Table 4

Summary of EFA analysis results of scales

\begin{tabular}{|c|c|c|c|c|c|}
\hline Factors & Scales of Measurement & KMO & Eigenvalues & Variance & Notes \\
\hline 1 & Service Quality (CLDV) & 0.896 & 3.668 & 73.362 & Accepted \\
\hline 2 & Information Quality (CLTT) & 0.880 & 3.365 & 67.294 & Accepted \\
\hline 3 & System Quality (CLHT) & 0.877 & 3.313 & 66.260 & Accepted \\
\hline 4 & IT skills (KTSD) & 0.832 & 3.067 & 76.668 & Accepted \\
\hline 5 & Students' perceptions (CNSV) & 0.859 & 3.276 & 65.522 & Accepted \\
\hline 6 & Students' Readiness (SSSV) & 0.806 & 2.641 & 66.032 & Accepted \\
\hline 7 & Online learning Quality (CLHTT) & 0.803 & 2.752 & 68.806 & Accepted \\
\hline 8 & Improving perceptions of accounting students & 0.853 & 3.408 & 85.209 & Accepted \\
\hline
\end{tabular}

As a result, all factors being analyzed have factor loading $>0.55$; Eigenvalue $>1$, all Sigs $=0.00<0.05$, showing that factor analysis is appropriate. Besides, all of the extracted variances of factors are $>50 \%$. Thus, the conduct of factor analysis explores the factors affecting the Online Learning Quality to improve accounting students' perceptions of Online learning provided by universities in Ho Chi Minh City. The scales after preliminary analysis remain the same and are used in official research through CFA affirmation factor analysis and testing of the research hypothesis by the Structural equation modeling (SEM) model in the research section.

Empirical Results of the Confirmatory Factor Analysis (CFA)

Table 5

Summary of CFA results with standardized regression weights (Standardized Regression Weights)

\begin{tabular}{ccccccccccccc}
\hline CLDT & $\leftarrow$ & CLDT & 0.847 & SNT1 & $\leftarrow$ & SNT & 0.92 & KNSD4 & $\leftarrow$ & KNSD & 0.883 \\
CLDT2 & $\leftarrow$ & CLDT & 0.837 & SNT2 & $\leftarrow$ & SNT & 0.901 & KNSD2 & $\leftarrow$ & KNSD & 0.871 \\
CLDT5 & $\leftarrow$ & CLDT & 0.869 & CLHT3 & $\leftarrow$ & CLHT & 0.759 & KNSD3 & $\leftarrow$ & KNSD & 0.859 \\
CLDT1 & $\leftarrow$ & CLDT & 0.707 & CLHT4 & $\leftarrow$ & CLHT & 0.777 & KNSD1 & $\leftarrow$ & KNSD & 0.735 \\
CLDT3 & $\leftarrow$ & CLDT & 0.832 & CLHT5 & $\leftarrow$ & CLHT & 0.744 & SSSV2 & $\leftarrow$ & SSSV & 0.772 \\
CLTT2 & $\leftarrow$ & CLTT & 0.792 & CLHT2 & $\leftarrow$ & CLHT & 0.759 & SSSV1 & $\leftarrow$ & SSSV & 0.775 \\
CLTT3 & $\leftarrow$ & CLTT & 0.78 & CLHT1 & $\leftarrow$ & CLHT & 0.743 & SSSV4 & $\leftarrow$ & SSSV & 0.696 \\
CLTT1 & $\leftarrow$ & CLTT & 0.813 & CNSV5 & $\leftarrow$ & CNSV & 0.812 & SSSV3 & $\leftarrow$ & SSSV & 0.717 \\
CLTT5 & $\leftarrow$ & CLTT & 0.741 & CNSV4 & $\leftarrow$ & CNSV & 0.763 & CLHTT2 & $\leftarrow$ & CLHTT & 0.818 \\
CLTT4 & $\leftarrow$ & CLTT & 0.719 & CNSV2 & $\leftarrow$ & CNSV & 0.813 & CLHTT1 & $\leftarrow$ & CLHTT & 0.784 \\
SNT3 & $\leftarrow$ & SNT & 0.867 & CNSV1 & $\leftarrow$ & CNSV & 0.718 & CLHTT4 & $\leftarrow$ & CLHTT & 0.754 \\
SNT4 & $\leftarrow$ & SNT & 0.918 & CNSV3 & $\leftarrow$ & CNSV & 0.607 & CLHTT3 & $\leftarrow$ & CLHTT & 0.74 \\
\hline
\end{tabular}


In the summary table of CFA results (Table 5) with standardized regression weights, all standardized weights are $>0.5$ so the observed variables of the scale have convergent values and P-value values are statistically significant. The results show that the model is suitable for the data with Chi - squared $=1172.665$; Degrees of freedom $=559 ; \mathrm{CMIN} / \mathrm{df}=2,098<3 ; \mathrm{P}$ value $=0.000$. Other measurement criteria also reached the required value: $\mathrm{CFI}=0.972>0.9 ; \mathrm{GFI}=0.938>0.9 ; \mathrm{TLI}=0.968>0.9$; RMSEA $=0.033<0.05$. All the weights of the variables are $>0.5, \mathrm{P}$ values $=0.000$ should be statistically significant.

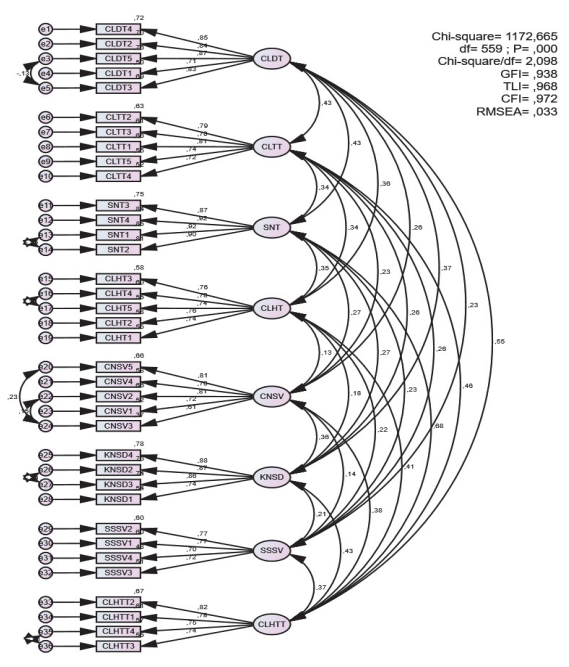

Fig. 2. CFA result model

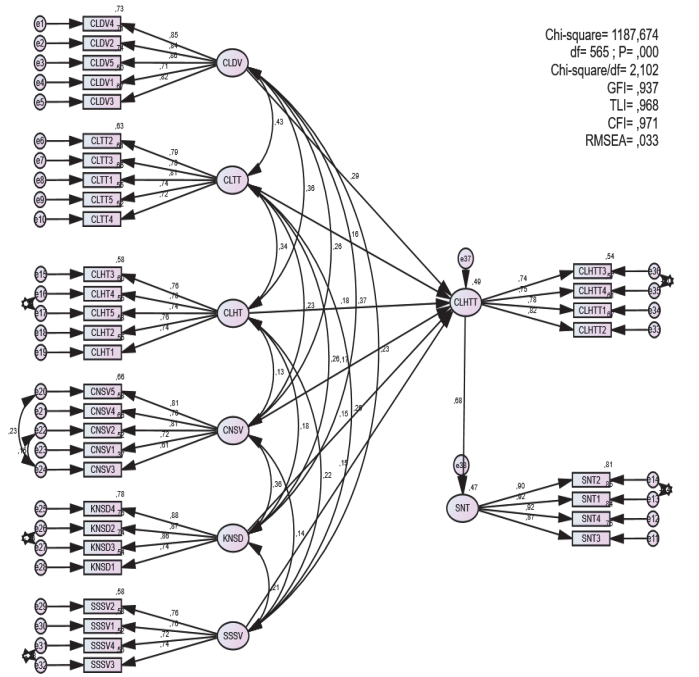

Fig. 3. SEM test results of the theoretical model

Testing theoretical models and research hypotheses with Structural equation modeling (SEM)

Testing theoretical models

The results show that the model has a good fit with data, Chi-squared $=1187.674$, degrees of freedom $=565$, CMIN $/ \mathrm{df}$ $=2.102<3$, P values $=0.000$. Other measurement criteria also met the required values: $\mathrm{TLI}=0.968 ; \mathrm{CFI}=0.971 ; \mathrm{GFI}=$ $0.937>0.9, \mathrm{RMSEA}=0.033<0.05$. All the weights of the variables are $>0.5, \mathrm{P}$ values $=0.000$ should be statistically significant. The indicators show that the theoretical model is suitable for the survey data. The results show that all relationships have a positive and direct impact on the Online Learning Quality to improving accounting students' perceptions of Online learning provided by universities in Ho Chi Minh City (See Fig. 2 and Fig. 3).

Table 6

$\underline{\text { Results of testing the causal relationship between concepts in the theoretical model }}$

\begin{tabular}{|c|c|c|c|c|c|c|}
\hline & & & Estimate & S.E. & C.R. & $\mathrm{P}$ \\
\hline \multirow{6}{*}{ Online Learning Quality } & $\leftarrow$ & Service Quality & .289 & .042 & 8.320 & $* * *$ \\
\hline & $\leftarrow$ & Information Quality & .164 & .027 & 4.935 & $* * *$ \\
\hline & $\leftarrow$ & System Quality & .176 & .034 & 5.496 & $* * *$ \\
\hline & $\leftarrow$ & Students' perceptions & .170 & .033 & 5.401 & $* * *$ \\
\hline & $\leftarrow$ & Students' readiness & .154 & .030 & 5.008 & $* * *$ \\
\hline & $\leftarrow$ & IT skills & .149 & .025 & 4.685 & $* * *$ \\
\hline Accounting students' perceptions & $\leftarrow$ & Online Learning Quality & .684 & .035 & 20.443 & $* * *$ \\
\hline
\end{tabular}

Table 6 shows that all the hypothesized relationships in the research model are proved by testing the SEM model. The results of estimating the weights are all positive $(+)$ and statistically significant. That proves the concepts in the theoretical model: Service Quality (CLDV); Information Quality (CLTT); System Quality (CLHT); IT skills (KTSD); Students' perceptions (CNSV); Students' Readiness (SSSV). The concept has a positive impact on the Online Learning Quality to improving accounting students' perceptions of Online learning provided by universities in Ho Chi Minh City.

Testing and estimating theoretical models with Bootstrap

The Bootstrap test is used to re-estimate the parameters in the theoretical model that are estimated by the optimal estimation method (Maximum Likelihood). In this study, we performed Bootstrap by repeated sampling with a sample size of $\mathrm{N}=1000$. The value of CR is less than 2 so we can confirm the bias is very small and not statistically significant in reliability $95 \%$. This proves that the estimates in the model are reliable. 
Table 7

Estimated results by Bootstrap with $\mathrm{N}=1000$

\begin{tabular}{|c|c|c|c|c|c|c|c|c|}
\hline \multicolumn{3}{|c|}{ Parameter } & SE & SE-SE & Mean & Bias & SE-Bias & $|\mathbf{C} . \mathbf{R}|$ \\
\hline \multirow{6}{*}{ Online Learning Quality } & $\leftarrow$ & Service Quality & 0.040 & 0.001 & 0.352 & 0.001 & 0.001 & 1 \\
\hline & $\leftarrow$ & Information Quality & 0.026 & 0.001 & 0.136 & 0.002 & 0.001 & 2 \\
\hline & $\leftarrow$ & System Quality & 0.032 & 0.001 & 0.182 & -0.002 & 0.001 & 2 \\
\hline & $\leftarrow$ & Students' perceptions & 0.031 & 0.001 & 0.176 & -0.001 & 0.001 & 1 \\
\hline & $\leftarrow$ & Students' readiness & 0.029 & 0.001 & 0.151 & 0.000 & 0.001 & 0 \\
\hline & $\leftarrow$ & IT skills & 0.025 & 0.001 & 0.114 & -0.001 & 0.001 & 1 \\
\hline Accounting students' perceptions & $\leftarrow$ & Online Learning Quality & 0.033 & 0.001 & 0.715 & 0.001 & 0.001 & 1 \\
\hline
\end{tabular}

Testing the research hypotheses

Table 8

Regression coefficient of the research model

\begin{tabular}{|c|c|c|c|c|c|c|c|}
\hline Hypothesis & Relati & nshi & & Estimate & S.E. & C.R. & $\mathbf{P}$ \\
\hline H1 & \multirow{6}{*}{ Online Learning Quality } & $\leftarrow$ & Service Quality & .289 & .042 & 8.320 & $* * *$ \\
\hline $\mathrm{H} 2$ & & $\leftarrow$ & Information Quality & .164 & .027 & 4.935 & $* * *$ \\
\hline $\mathrm{H} 3$ & & $\leftarrow$ & System Quality & .176 & .034 & 5.496 & $* * *$ \\
\hline $\mathrm{H} 4$ & & $\leftarrow$ & Students' perceptions & .170 & .033 & 5.401 & $* * *$ \\
\hline $\mathrm{H} 5$ & & $\leftarrow$ & Students' readiness & .154 & .030 & 5.008 & $* * *$ \\
\hline H6 & & $\leftarrow$ & IT skills & .149 & .025 & 4.685 & $* * *$ \\
\hline $\mathrm{H} 7$ & Accounting students' perceptions & $\leftarrow$ & Online Learning Quality & .684 & .035 & 20.443 & $* * *$ \\
\hline
\end{tabular}

After the overall structure model is analyzed and tested, the next step is to look at the estimated values to examine causal relationships. Through the above data table, we see that all factors have a positive impact on the Online Learning Quality in universities in Ho Chi Minh City. The Service Quality is the strongest factor (standardized weight is 0.289). The second most powerful factor is the System Quality (standardized weight is 0.176). The third most powerful factor is the Students' perceptions (standardized weight is 0.170 ). The fourth is the Information Quality level factor with a standardized weight of 0.164 , the fifth is the Students' readiness factor (standardized weight is 0.154). Finally, the IT skills (standardized weight is 0.149 ) have the lowest impact. There is a strong correlation between the Online Learning Quality and the improvement of accounting students' perceptions of Online learning provided by universities in Ho Chi Minh City. Estimated results show that this hypothesis is accepted and achieved a standardized beta value of 0.684 with significance level $\mathrm{P}=0.000<0.05$. This result confirms the positive relationship and the impact between factors the Online Learning Quality to improve accounting students' perceptions of the Online learning provided by universities in Ho Chi Minh City. We have P-value $=$ Sig. $=0.000<0.05$ and the value of standardized beta equals 0.684. If the Online Learning Quality changes by 1 point (level), it will increase the accounting students' perceptions of the Online learning provided by universities in Ho Chi Minh City (or decrease) 0.684 points without considering the other factors.

\section{Conclusion and managerial implication}

In conclusion, the findings confirmed the appropriateness of the research model. All the information collected, analytical methods, and the results showed the direct relationship between service quality, information quality, system quality, IT skills, students' perceptions and students' awareness of Industry 4.0 with quality of online learning system. Based on the findings, accounting students' perceptions of online learning in universities in Ho Chi Minh City can be improved. Based on the results and findings of the research, the authors gave out several recommendations and suggestions to improve the quality of online learning systems, from which enhancement can be made to students' perceptions and intentions to use online learning methods continuously. Universities need to ensure the quality of online learning systems by establishing management boards and issuing regulations and guidelines for implementation. Aside from those, lecturers need to provide curriculum, course material, and information regarding the courses so students can prepare before taking the courses. It is also necessary to have standards and benchmark to measure the actual levels of lecturers after a specific period of teaching time. Universities need to invest in equipment, systems, as well as learning material to ensure the quality of information and online systems. Aside, lecturers should exchange IT skills with others, and make necessary preparations before class to be able to avoid technical errors and provide more online learning material so students can download and store for revision. Aside from that, lecturers need to observe and identify students' weaknesses and strengths, as well as obstacles that students encounter to provide guidelines and support throughout the courses. It is also necessary to reduce students' waiting time to get responses and helps by creating a fanpage administrated by lecturers or departmental staffs to manage all feedbacks and requests from students. Last but not least, lecturers should try to motivate students so they can be confident enough to keep enrolling online courses. Students should focus on improving IT skills to ensure that they are ready to participate in learning and research activities using online tools and methods in Industry 4.0. Universities should provide workshops and seminars to equip students with necessary skills and techniques for online courses. Besides, it is students' duty to revise material, prepare for the next chapters before every class; most importantly, students should utilize the online learning system to acquire deeper understanding of those lessons 
provided in classes. Students should also actively join those clubs in universities, especially IT clubs; lecturers should coordinate with club leaders to provide guidance regarding club meetings to improve students' IT skills.

\section{References}

Alsabawy, A.Y., Cater-Steel, A., \& Soar, J. (2016). Determinants of perceived usefulness of online learning systems. Computers in Human Behavior, 64, 843-858.

Asiry, M.A. (2017). Dental students' perceptions of an online learning. Saudi Dental Journal, 29, 167-170.

Bollen, K.A. (1989). Structural Equations with Latent Variables. John Wiley and Sons, Inc., New York.

Bonekamp, L., \& Sure, M. (2015). Consequences of industry 4.0 on human labour and work organisation. Journal of Business and Media Psychology, 6(1), 33-40.

Chiu, C.M., Hsu, M.H., Sun, S.Y., Lin, T.C., \& Sun, P.C. (2005). Usability, quality, value and online learning continuance decisions. Computers \& Education, 45(4), 399-416.

Chiu, C.M., Sun, S.Y., Sun, P.C., \& Ju, T.L. (2007). An empirical analysis of the antecedents of web-based learning continuance. Computer \& Education, 49(4), 1224-1245

Dağhan, G. \& Akkoyunlu, B. (2016). Modeling the continuance usage intention of online learning environments. Computers in Human Behavior, 60, 198-211.

DeLone, W.H. \& McLean, E.R. (1992). Information systems success: The quest for the dependent variable. Information Systems Research, 3(1), 60-95.

DeLone, W.H. \& McLean, E.R. (2003). The DeLone and McLean Model of Information Systems Success: A TenYear Update. Journal of Management Information Systems, 19(4), 9-30.

Dung, T. Q et al.( 2018). Cuộc cách mạng công nghiệp lần thứ tư về sự tác động đến phương pháp dạy học ở đại học hiện nay, Tạo chí Giáo dục, Số đặc biệt Kỳ 2 tháng 5/2018. Tr 94-97.

Kagermann, H. (2014). Chancen von industrie 4.0 nutzen, In T. Bauernhansl, M. ten Hompel \& B. Vogel-Heuser, (Ed.). Industrie 4.0 in Produktion, Automatisierung und Logistik. Anwendungen Technologien Migration. Wiesbaden: Springer. pp: $603-614$

Kim, B. \& Oh, J. (2011). The difference of determinants of acceptance and continuance of mobile data services: A value perspective. Expert Systems with Applications, 38, 1798-1804.

Kukulska-Hulme, A. (2012). How should the higher education workforce adapt to advancements in technology for teaching and learning? The Internet and Higher Education, 15(4), 247-254.

Liao, C., Palvia, P., \& Chen, J.L. (2009). Information technology adoption behavior life cycle: Toward a Technology Continuance Theory (TCT). International Journal of Information Management, 29, 309-320.

Panigrahi, R., Srivastava, P.R., \& Sharma, D. (2018). Online learning: Adoption, continuance, and learning outcome-A review of literature. International Journal of Information Management, 43. 1-14.

Parasuraman, A., Zeithaml, V. A., \& Berry, L. L. (1994). Reassessment of expectations as a comparison standard in measuring service quality: implications for further research. Journal of Marketing, 58(1), 111-124.

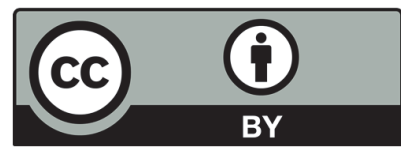

(C) 2020 by the authors; licensee Growing Science, Canada. This is an open access article distributed under the terms and conditions of the Creative Commons Attribution (CC-BY) license (http://creativecommons.org/licenses/by/4.0/). 